\title{
Tracing conceptual understandings and misunderstandings of science by students with and without vision impairment through a pilot study: the case of density and heat
}

\author{
Vassilios Argyropoulos ${ }^{1}$ and Christos Yfantis ${ }^{1}$
}

${ }^{1}$ University of Thessaly, Volos, Greece

HOW TO CITE:
Argyropoulos, V., Yfantis, C.

(2021).

Tracing conceptual

understandings

and misunderstandings

of science by students with

and without vision impairment

through a pilot study: the case

of density and heat. International

Journal of Special Education,

36(1), 77-88

CORRESPONDING AUTHOR:

Vassilios Argyropoulos; vassargi@uth.gr

DOI:

https://doi.org/10.52291/

ijse.2021.36.8

\section{COPYRIGHT STATEMENT:}

Copyright: (C) 2021 Authors.

Open access publication under the terms and conditions of the Creative Commons

Attribution (CC BY)

license (http://creativecommons.

org/licenses/by/4.0/).

\begin{abstract}
The purpose of this pilot study was to describe and analyze the perceptions and alternative ideas of individuals with and without vision impairments regarding the concepts of "density" and "heat". The perceptions of sighted, age- and gender-matched participants were compared with those of visually impaired participants (two groups). Semi-structured interviews were conducted, and the analysis of the data followed the method of tracing and developing categories and sub-categories. The analysis revealed that the two groups held diverse understandings about "density", while most participants seemed to identify "heat" as "temperature" and vice versa. The results are presented in the form of conception correlation matrices highlighting common concepts and alternative ideas towards the notions of "density" and "heat". The findings demonstrate that in both groups there are common patterns of alternative ideas, which may lead to the assumption that vision loss or blindness and proficiency in science do not constitute a causal relation. The results may lead to useful implications for differentiated instruction regarding the comprehension of science in an integrated educational setting in conjunction with technological advances and inclusive practices.
\end{abstract}

Keywords: blindness; science; heat; density; alternative ideas; expanded core curriculum; differentiated instruction 


\section{INTRODUCTION}

Based on relevant research, it is documented that students with vision impairment, exhibit the same range of cognitive abilities and intellectual capacities as their sighted peers (Kumar, Ramasamy, \& Stefanich, 2001). Students with vision impairment have the potential and the capacity to master higher-order science concepts as do their sighted peers, provided that the obstacles they encounter are being alleviated (Jones, Minogue, Oppewal, Cook, \& Broadwell, 2006; Kumar, Ramasamy, \& Stefanich, 2001; Sahin \& Yorek, 2009). The role of assistive technology has played pivotal role in science learning regarding students with vision impairment. All of the technological advances that have been designed, developed, and used in the education of students with vi are aimed at one universal goal: access to information. Such examples may be the following: embossers (printers which produce tactile graphs and diagrams), tape or digital recorders, talking calculators, scanners, 3-D printers, computer with specialized software such as Jaws or Supernova, other braille software, handheld magnifiers, braille displays, optical characters recognition systems, synthetic speech software, Kurzweil reading machine, braille, and other low vision aids such as closed-circuit television (Argyropoulos \& Ravenscroft, 2019; Nkiko, Atinmo, Michael-Onuoha, Ilogho, Fagbohun, Ifeakachuku, O., Adetomiwa B., Usman, 2018; Azeta et al., 2018; Eligi \& Mwantimwa, 2017; Beal \& Rosenblum, 2015; Matchinkski \& Winters, 2016).

Although assistive technological advances seem to be very promising regarding the removal of barriers in the learning process, science teachers receive inadequate level of preparation regarding the use of assistive technology (Ambrose-Zaken \& Bozeman, 2010; Maguvhe, 2015; Wild \& Allen, 2009). Hence, evidence-based data regarding science coupled with teaching materials and teaching strategies for students with vision impairment are rather limited (Jones, Minogue, Oppewal, Cook, \& Broadwell, 2006; Maguvh, 2015). Moreover, the number of studies that have sought to examine how people with visual impairments approach and conceptualize scientific concepts is limited (Jones, Taylor, \& Broadwell, 2009). More specifically, the studies which have investigated blind students' scientific concepts fall into the following thematic areas: linear size, measurement and scale (Jones, Forrester, Robertson, Gardner, \& Taylor, 2012; Jones, Taylor, \& Broadwell, 2009), nature of matter (Smothers \& Goldston, 2009), features of living organisms and life science (Fraser \& Maguvhe, 2008; Jaworska-Biskup, 2011; Wild, 2010), seasonal change (Wild \& Trundle, 2010), colors, natural phenomena, physical processes (Jaworska-Biskup, 2011), chemical reactions (Micklos, Lewis, \& Bodner, 2013), geological concepts (Wild, Hilson, \& Farrand, 2013), as well as nature and sound (Wild, Hilson, \& Hobson, 2013).

For example, notions such as dissolution, chemical change, expansion, condensation, rotation and orbits, gravity, mass, and weight, have been investigated in the above studies with samples consisting of students with and without vision impairments (Smothers \& Goldston, 2009; Wild, 2010; Wild \& Trundle, 2010). It was found that students with blindness or severe vision impairments tended to develop two mind maps (Smothers \& Goldston, 2009); one for the internal functional system of the particles and another one for the external function, namely the interaction of the particles of a body with its environment. Also, it was conjectured in many studies that specialized support was vital to the enhancement of blind students' understanding and conceptualization of science, such as pin-dot diagrams, 3D diagrams, 3D models as well as modeling kits (Betts \& Cross, 2010).

The finding of the above studies cannot be generalized because the samples were very small; nevertheless, there was a common outcome that participants who had vision impairment had developed a science notion system which consisted of correct and incorrect ideas; the latter is known as "alternative ideas". It has to be mentioned here that the term "alternative ideas" indicate students' ideas regarding nature, physical phenomena and reasoning which may differ from the theories the science teacher may wish to develop. These ideas are referred to as alternative conceptions (Wandersee, Mintzes, \& Novak, 1994) and usually deviate from textbooks which constitute the dominant teaching tool in schools and colleges. Additionally, these ideas may be developed without instruction or with very little guidance from teachers and, as a result, they are also called naive theories as they usually incorporate misconceptions (Rosengren \& Brawell, 2002).

Alternative ideas have been traced in all students with and without vision impairments and many researchers have arrived at conflicting outcomes regarding the existence of same or different patterns of alternative ideas in both populations. So far, pilot studies with students with and without vision impairment have been conducted, which investigate concepts related to matter, space 
and time, motion and forces, chemical equations, optics and light, and sound.

To our knowledge, no research has investigated how individuals with vision impairments conceptualize and elaborate the concepts of "density" and "heat" and the characteristics of matter at different physical states (solid, liquid, gas).

\section{Hence, the research objectives of the present study are as follows:}

1. To investigate blind and sighted students' ideas about the concepts of "density" and "heat" and find out -if any- common patterns among them

2. To investigate blind and sighted students' alternative ways of thinking about the concepts of "density" and "heat" by categorizing and comparing them

\section{METHOD}

\section{Participants}

Eight individuals participated in the present study and were equally divided in two subgroups. Members of the first subgroup were individuals with sever vision impairments (i.e. congenitally blind), they did not have additional disabilities and they were enrolled in a mainstream high school (12th graders, three females and one male students). Members of the first subgroup were of the same age and were efficient braille readers. The second subgroup consisted of sighted individuals, and the two subgroups were matched by two factors: a. gender, and b. age.

According to the Greek National Curriculum, the notions of "heat" and "density" are introduced to students beginning with the 5th grade, and they are working out these notions throughout school years, in their science classes. Thus, all participants were familiarized with the notion of "heat" and "density", respectively.

Also, it has to be mentioned that the authors followed the ethical principles of the Declaration of Helsinki and obtained signed consent from the participants using the appropriate forms and procedures suggested by the World Medical Association.

\section{Instruments}

Data were obtained via face-to-face semi-structured interviews (Merriam, 2009). The authors developed two interview guides structured on three main axes: a. de- finition(s) and descriptions of the physical concepts in question (i. e. heat and density), b. relations between physical concepts and their appearance in the physical world, and c. physical properties. All items in the interview guides were organized according to the previous main axes and included open-ended questions. The purpose of using open-ended questions rather than rating items was to obtain as much information as possible about the participants' insights and experiences towards the specific notions of heat and density. In addition, the authors examined in advance that these specific notions of heat and density had been taught in the participants' classes, according to the National Curriculum, and the use of Greek textbooks provided the basis for formulating the conceptual questions from which the two interview-guides were developed.

The topics of the interviews were based on the respective content of the Science textbooks of the Greek public primary schools. In order to ensure the external validity of the tool (Cohen, Manion, \& Morrison, 2007), the questions were evaluated in terms of scientific content and wording - by two experienced science teachers who were working at the university- and were updated on the basis of the data obtained. Questions were also modified during pilot studies with other students who did not participate in the main study. The studies took place before the main research

\section{Research Design}

Individual meetings were set up and the number of meetings differed depending on each participant's availability. Most interviews were conducted at the participants' schools or at their homes. The authors asked the participants questions about their knowledge of these very distinct science concepts (i. e. heat and density) and then the authors proceeded into secondary questions based upon participants' responses. The whole session lasted approximately one hour per participant and all dialogues were recorded.

\section{Data Analysis}

The authors used Dey's (1993) recommendations in developing categories into broad categories, "middle-order" categories, and sub-categories using the "bit-by-bit" data analysis. The analysis began with the verbatim transcription of the interview recordings. Then, the transcribed interviews were clustered in sentences, phrases, and words. Finally, the authors organized the data into broad categories based on the core themes of the semi-structured interviews. 
Table 1. Blind participants' common concepts towards notions relevant to "density".

\begin{tabular}{|c|c|c|c|c|c|c|}
\hline \multirow{12}{*}{ 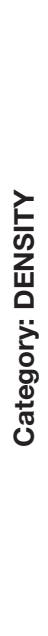 } & Sub-category & Key - conceptions & B1F & B2F & B3M & B4F \\
\hline & \multirow{11}{*}{$\begin{array}{c}\text { Characteristics } \\
\text { of matter }\end{array}$} & Solid state is a state of matter & $\bullet$ & $\bullet$ & $\bullet$ & $\bullet$ \\
\hline & & Liquid state is a state of matter & $\bullet$ & $\bullet$ & & $\bullet$ \\
\hline & & Gas state is a state of matter & - & • & & $\bullet$ \\
\hline & & Air is everywhere & $\bullet$ & $\bullet$ & $\bullet$ & $\bullet$ \\
\hline & & Air can be perceived only by the senses & $\bullet$ & $\bullet$ & $\bullet$ & $\bullet$ \\
\hline & & Solid bodies have fixed shapes & $\bullet$ & $\bullet$ & • & $\bullet$ \\
\hline & & Liquids do not have fixed shapes & $\bullet$ & $\bullet$ & $\bullet$ & $\bullet$ \\
\hline & & Gases have fixed shapes & $\bullet$ & - & $\bullet$ & $\bullet$ \\
\hline & & Solids do not have a fixed volume & $\bullet$ & $\bullet$ & $\bullet$ & $\bullet$ \\
\hline & & Liquids have a fixed volume & $\bullet$ & & $\bullet$ & $\bullet$ \\
\hline & & Gasses have a fixed volume & $\bullet$ & $\bullet$ & $\bullet$ & $\bullet$ \\
\hline
\end{tabular}

Anonymity of the participants was obtained through allocation of a three-character code (two letters and one digit) per each individual. The first character (letter) of each code indicated the presence of vision impairment or not ("B" for Blind/Visually Impaired and "S" for Sighted participants). The second character (digit) indicated the seriation of each participant. The third character (letter) indicated the gender of the participant ("F" for female, "M" for Male).

Both authors read the transcribed data and developed all types of categories and then compared them. When a discrepancy in coding or in categorization was traced, the specific item(s) was/were revised on the basis of the original data. The authors separately developed categories and subcategories during the qualitative analysis of the obtained data. In order to ensure reliability, they measured the inter-individual concordance rate (Robson, 2002) twice. The initially calculated concordance rate was $90 \%$, and after discussion, the concordance rate reached $98 \%$ for all category types.

\section{RESULTS}

Two criteria were used to present the results. The first one refers to participants' common conceptions about density and heat and the second one refers only to participants' alternative conceptions. Hence, the below tables constitute an aggregated description of these conceptions providing input from both groups (i. e. students with and without vision impairment). This approach has adopted elements of a between and within study without following the rigorous character of an experimental de- sign. It is based on pragmatic content formulating conception correlation matrices (Soltanifar \& Ansari, 2016).

\section{Investigating Concepts about "Density"}

The interviews covered a variety of topics, such as states of matter, characteristics of matter at different physical states, volume, and density of a physical body. All participants were invited to reflect on these topics and make their own statements based on their knowledge or their understanding. Table 1 presents blind participants' common notions towards density through characteristics of matter, whereas no common concepts were found regarding definitions of volume and density.

Most participants with vision impairment acknowledged that all physical bodies may be found in solid, liquid or gaseous state (states of matter). Participants seemed to share a common understanding about the shape and the volume of a solid body. They held the view that the shape of a solid body is fixed, while its volume may differ depending on its placement within the environment. It seems that they had developed a notion of relationship between the location of solid objects and their volume ( $i$. e. alternative idea). Regarding the shape and volume of a liquid body, most of the participants held the same view (i. e. "Liquids do not have fixed shapes" see Table 1) and this view was in line with all common science textbooks.

Concerning gas bodies, most participants with vision impairment stated that their shape and volume is definite (i. e. alternative conception). Finally, what is interesting to mention here is that nearly all participants with vision impairment were not happy with the idea that ga- 


\begin{tabular}{|c|c|c|c|c|c|c|}
\hline \multirow{17}{*}{ 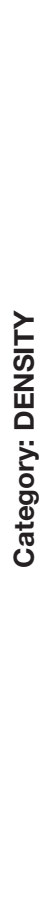 } & Sub-categories & Key - conceptions & S1F & S2F & S3M & S4F \\
\hline & \multirow{11}{*}{$\begin{array}{c}\text { Characteristics } \\
\text { of matter }\end{array}$} & Solid state is a state of matter & & & $\bullet$ & $\bullet$ \\
\hline & & Liquid state is a state of matter & & & • & $\bullet$ \\
\hline & & Gas state is a state of matter & & & • & • \\
\hline & & Air is everywhere & • & $\bullet$ & $\bullet$ & • \\
\hline & & Air can be perceived only by the senses & $\bullet$ & & $\bullet$ & $\bullet$ \\
\hline & & Solids have fixed shapes & $\bullet$ & $\bullet$ & $\bullet$ & $\bullet$ \\
\hline & & Liquids do not have fixed shapes & $\bullet$ & $\bullet$ & $\bullet$ & $\bullet$ \\
\hline & & Gases have fixed shapes & $\bullet$ & - & & $\bullet$ \\
\hline & & Solids have fixed volume & $\bullet$ & & $\bullet$ & - \\
\hline & & Liquids have fixed volume & $\bullet$ & & $\bullet$ & $\bullet$ \\
\hline & & Gases have fixed volume & $\bullet$ & - & $\bullet$ & • \\
\hline & Definition of volume & Space occupied by a physical body & $\bullet$ & & & $\bullet$ \\
\hline & \multirow{4}{*}{ Definition of density } & Distances between atoms & $\bullet$ & $\bullet$ & • & $\bullet$ \\
\hline & & Something to do with the volume of a substance & $\bullet$ & $\bullet$ & $\bullet$ & $\bullet$ \\
\hline & & Something to do with the mass of a substance & $\bullet$ & • & • & • \\
\hline & & Something to do with the weight of a substance & $\bullet$ & $\bullet$ & & \\
\hline
\end{tabular}

ses are matter with no shape or size. They believed that air was enclosed in spaces, and people could recognize its presence by its mass when the wind blew.

The content of Table 2 depicts the corresponding common conceptions of the sighted participants towards "density". Based on the conducted analysis, three subcategories emerged; that is, characteristics of matter, definition of volume, and definition of density.

When the sighted participants were invited to describe the states in which physical bodies can be found naturally, only two of them referred to three states of matter (i. e. solids, liquids and gases). The other two participants believed that it is wrong to categorize substance into specific states of matter. It is worth emphasizing here that when the sighted participants were asked to elaborate on the shape and volume of gases, they supported the view that they are definite (see Table 2). This conception constitutes an alternative idea and there were members from both groups (participants with and without vision) who embraced it.

Unlike participants with vision impairment, members from the group of the sighted participants, attempted to define the concepts of volume and density of objects, whereas none of the participants who were blind attempted to do so. According to their definitions, volu- me is the amount of space occupied by the object, and density reflects the distance between the atoms which compose the object (see Table 2). In addition, the participants S3M and S4F were closer regarding the fundamental characteristics of the notion "density", whereas S1F and S2F, seemed to have adopted an intuitive rather than a scientific understanding about density. To conclude, despite the fact that the sighted participants referred to critical variables of "density" (i. e. mass and volume), they did not carry on to a quantitative approach (e. g. ratio) or to a qualitative approach (e. g. density is a valid measure to identify a substance).

\section{Investigating Common Concepts about "Density"}

Table 3 incorporates common conceptions from both groups. Three sub-categories were also traced in this conceptual correlation matrix: a. characteristics of matter, b. definition of volume, and c. definition of density. Most participants acknowledged three states of matter (i. e. solids, liquids, and gases), and held the view that air exists only in enclosed spaces and the only way to trace its presence is when the wind blows. Differences were also traced between the members of the two groups. Regarding solid objects, almost all participants stated that their shape is fixed. On the contrary, when they were asked to comment on their volume, sighted participants claimed that solids can hold their own shape, whereas 

common concepts towards notions relevant to "density".

\begin{tabular}{|c|c|c|c|c|c|c|c|c|c|c|}
\hline \multirow{20}{*}{ 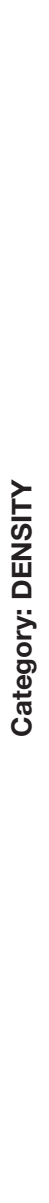 } & Sub-categories & Key - conceptions & B1F & B2F & B3M & B4F & S1F & S2F & S3M & S4F \\
\hline & \multirow{14}{*}{$\begin{array}{l}\text { Characteristics } \\
\text { of matter }\end{array}$} & Solid state is a state of matter & $\bullet$ & $\bullet$ & $\bullet$ & - & & & - & $\bullet$ \\
\hline & & Liquid state is a state of matter & $\bullet$ & $\bullet$ & & $\bullet$ & & & $\bullet$ & $\bullet$ \\
\hline & & Gas state is a state of matter & $\bullet$ & $\bullet$ & & $\bullet$ & & & - & $\bullet$ \\
\hline & & Air is everywhere & & - & $\bullet$ & $\bullet$ & $\bullet$ & - & $\bullet$ & $\bullet$ \\
\hline & & Air can be perceived only by the senses & $\bullet$ & $\bullet$ & - & $\bullet$ & $\bullet$ & & $\bullet$ & $\bullet$ \\
\hline & & Solids have fixed shapes & & $\bullet$ & $\bullet$ & $\bullet$ & $\bullet$ & $\bullet$ & - & $\bullet$ \\
\hline & & Liquids have fixed shapes & $\bullet$ & & & & $\bullet$ & & & \\
\hline & & Liquids do not have fixed shapes & & $\bullet$ & $\bullet$ & $\bullet$ & & $\bullet$ & $\bullet$ & $\bullet$ \\
\hline & & Gases have fixed shapes & $\bullet$ & $\bullet$ & $\bullet$ & - & $\bullet$ & $\bullet$ & & $\bullet$ \\
\hline & & Solids do not have fixed volume & $\bullet$ & & & & $\bullet$ & & $\bullet$ & $\bullet$ \\
\hline & & Solids do not have fixed volume & & $\bullet$ & $\bullet$ & $\bullet$ & & $\bullet$ & & \\
\hline & & Liquids have fixed volume & $\bullet$ & & $\bullet$ & $\bullet$ & $\bullet$ & & $\bullet$ & $\bullet$ \\
\hline & & Liquids do not have fixed volume & & $\bullet$ & & & & - & & \\
\hline & & Gases have fixed volume & $\bullet$ & $\bullet$ & $\bullet$ & $\bullet$ & & $\bullet$ & $\bullet$ & $\bullet$ \\
\hline & Definition of volume & Space occupied by an object & & & & $\bullet$ & $\bullet$ & & & - \\
\hline & \multirow{4}{*}{$\begin{array}{l}\text { Definition } \\
\text { of density }\end{array}$} & $\begin{array}{l}\text { Something to do with the volume } \\
\text { of a substance }\end{array}$ & & & & - & & $\bullet$ & - & - \\
\hline & & $\begin{array}{l}\text { Something to do with the weight } \\
\text { of a substance }\end{array}$ & & & & - & $\bullet$ & $\bullet$ & & \\
\hline & & $\begin{array}{l}\text { Something to do with the space } \\
\text { occupied by the substance }\end{array}$ & & & $\bullet$ & & $\bullet$ & & & $\bullet$ \\
\hline & & $\begin{array}{l}\text { Something to do with the material } \\
\text { of the substance }\end{array}$ & & & $\bullet$ & & & $\bullet$ & & \\
\hline
\end{tabular}

most participants with vision impairment held the view that the shape of solids depends on their placement in the environment. In addition, almost all participants agreed that liquids assume the shape of the part of the container which they occupy, whereas they held the view that gases retain a fixed shape (see Table 3). Finally, the number of common conceptions regarding volume and density is much smaller, compared with the other two sub-categories - and it seems that the participants without vision impairment elaborated more on these notions.

\section{Investigating Alternative ideas about "Density"}

According to the participants with vision impairment, air is conceptualized as an "entity" without substance ("non -material body", see first column of Table 4) and according to them, its existence can be traced only by its flow. As far as the notion of shape is concerned, some participants argued that the shapes of liquids and gases are fixed, whereas solids do not retain a fixed shape. Their shape depends on their orientation in the environment. Also, it seems that the participants with vision impairment, for some re- ason, have developed certain intuitive notions regarding the notion "volume" which was contrary to formal science education they had received (see Table 4). Finally, what is interesting to underline is the causal relationship which participants with vision impairment have adopted; that is the bigger an object is, the higher the density and vice versa (see first column of Table 4).

The alternative ideas of the sighted students are quite similar to the ideas expressed by the participants with vision impairment (see second column of Table 4). It seems that the characteristics of gases, liquids, and solids, such as shape and volume, creates confusion to individuals irrespective of the vision condition. In terms of the notion "density", the participants who had no vision impairment had many misunderstandings regarding relationships between density and weight as well as between density and volume (see statements in second column of Table 4).

Comparing the first two columns of Table 4, it is conjectured that the common alternative ideas between 
Table 4.

Alternative ideas of participants with and without vision impairments (vi) towards "density".

\begin{tabular}{|c|c|c|c|}
\hline & participants' statements (with vi) & participants' statements (without vi) & Common statements \\
\hline AIR & $\begin{array}{l}\text { "Air isn't something that you can } \\
\text { touch...it's non-material body" } \\
\text { "The existence of the air is justified } \\
\text { when the wind blows" }\end{array}$ & $\begin{array}{l}\text { "You can recognize the air } \\
\text { only by air currents" }\end{array}$ & $\begin{array}{l}\text { "Air isn't something that you can } \\
\text { touch...it's non-material" } \\
\text { "The existence of the air is justified } \\
\text { when the wind blows" } \\
\text { "You can recognize the air only } \\
\text { by air currents" }\end{array}$ \\
\hline SHAPE & $\begin{array}{l}\text { "When you change the orientation } \\
\text { of a solid in the environment then } \\
\text { its shape also changes" } \\
\text { "Liquids and gases have fixed shape" }\end{array}$ & $\begin{array}{l}\text { "Liquids and gases } \\
\text { have fixed shape" }\end{array}$ & $\begin{array}{l}\text { "When you change the orientation } \\
\text { of a solid in the environment then } \\
\text { its shape also changes" } \\
\text { "Liquids and gases have fixed shape" }\end{array}$ \\
\hline WEIGHT & - & $\begin{array}{l}\text { "The weight of a solid substance } \\
\text { decreases when it turns into liquid" } \\
\text { "The weight of a liquid increases } \\
\text { when it turns into solid" }\end{array}$ & - \\
\hline VOLUME & $\begin{array}{c}\text { "Gases retain a fixed volume" } \\
\text { "The volume of a solid changes } \\
\text { when you fold it, for example a piece } \\
\text { of paper" } \\
\text { "The volume of a solid may change } \\
\text { when you change its position" } \\
\text { "The volume of a liquid changes } \\
\text { when you change its container" }\end{array}$ & $\begin{array}{l}\text { "Liquids do not retain a fixed volume" } \\
\text { "Gases retain a fixed volume" }\end{array}$ & $\begin{array}{l}\text { "Gases retain a fixed volume" } \\
\text { "The volume of a solid changes } \\
\text { when you fold it, for example } \\
\text { a piece of paper" } \\
\text { "The volume of a solid may } \\
\text { change when you change its position" } \\
\text { "The volume of a liquid changes } \\
\text { when you change its container" } \\
\text { "Liquids do not retain a fixed volume" } \\
\text { "Gases retain a fixed volume" }\end{array}$ \\
\hline DENSITY & $\begin{array}{l}\text { "Density depends exclusively } \\
\text { on the mass of the substance" } \\
\text { "Small objects have low density; } \\
\text { big objects must have higher density" }\end{array}$ & $\begin{array}{l}\text { "Density is identical to volume" } \\
\text { "Density is linked to the weight } \\
\text { of the object" } \\
\text { "The density of a solid substance } \\
\text { decreases when it turns into liquid" }\end{array}$ & - \\
\hline
\end{tabular}

Table 5.

Common patterns in the elaborations of participants with vision impairment towards the concept of "heat".

\begin{tabular}{|c|c|c|c|c|c|c|}
\hline \multirow{7}{*}{ 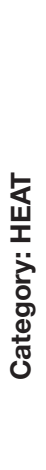 } & Sub-categories & Key - conceptions & B1F & B2F & B3M & B4F \\
\hline & heat & Sun is a source of heat & - & & $\bullet$ & $\bullet$ \\
\hline & \multirow[t]{2}{*}{ temperature } & Extreme temperature events are those below $00 \mathrm{C}$ & & $\bullet$ & $\bullet$ & $\bullet$ \\
\hline & & Temperature changes are due to natural phenomena & & & $\bullet$ & • \\
\hline & \multirow{3}{*}{$\begin{array}{c}\text { temperature } \\
\text { changes }\end{array}$} & When a solid turns into liquid then its temperature decreases & $\bullet$ & & & $\bullet$ \\
\hline & & When a liquid turns into gas then its temperature increases & & $\bullet$ & & • \\
\hline & & When a liquid turns into gas then its temperature decreases & $\bullet$ & & $\bullet$ & \\
\hline
\end{tabular}

participants with and without vision impairment were traced in the notions of the air, shape and volume (see third column of Table 4).

\section{Investigating Concepts about "Heat"}

The analysis of the comments and reflections of the participants with vision impairments upon the notion of "heat" revealed three sub-categories: $a$. the notion of heat, b. the notion of temperature, and c. temperature changes (see Ta- ble 5). All participants were invited to express their opinion upon definitions of heat, temperature as well as to make comments on temperature changes during changing states of matter. Their reflections and elaboration on these entities were more intuitive rather than scientific. For example, when they were asked to comment on temperature changes when matter moves from one state to another, keeping pressure constant, their responses seemed to be very confusing without a robust reasoning (see Table 5). 
Table 6.

Common patterns in the elaborations of participants with no vision impairment towards the concept of "heat".

\begin{tabular}{|c|c|c|c|c|c|c|}
\hline \multirow{11}{*}{ 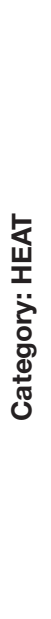 } & Sub-categories & Key - conceptions & S1F & S2F & S3M & S4F \\
\hline & \multirow{2}{*}{ heat } & It is the procedure of transfer & • & $\bullet$ & & \\
\hline & & Heat is about how cold or how hot a substance is & & $\bullet$ & & $\bullet$ \\
\hline & \multirow{4}{*}{ temperature } & Objects have different surface temperature & $\bullet$ & & $\bullet$ & • \\
\hline & & Temperature has an impact on the state of a substance & & & $\bullet$ & $\bullet$ \\
\hline & & Temperature changes relate to weather changes & & $\bullet$ & & $\bullet$ \\
\hline & & $\begin{array}{l}\text { Extreme values of temperature are considered } \\
\text { those found in icebergs or heat waves }\end{array}$ & & $\bullet$ & & $\bullet$ \\
\hline & \multirow{4}{*}{$\begin{array}{l}\text { Temperature } \\
\text { changes }\end{array}$} & When a liquid turns into solid then its temperature decreases & - & $\bullet$ & - & $\bullet$ \\
\hline & & When a solid turns into liquid then its temperature increases & - & $\bullet$ & $\bullet$ & $\bullet$ \\
\hline & & When a liquid turns into gas then its temperature increases & $\bullet$ & & - & $\bullet$ \\
\hline & & When you boil a substance then its temperature increases & & & $\bullet$ & - \\
\hline
\end{tabular}

Table 7.

An aggregated conceptual correlation matrix regarding common concepts towards the notions relevant to "heat".

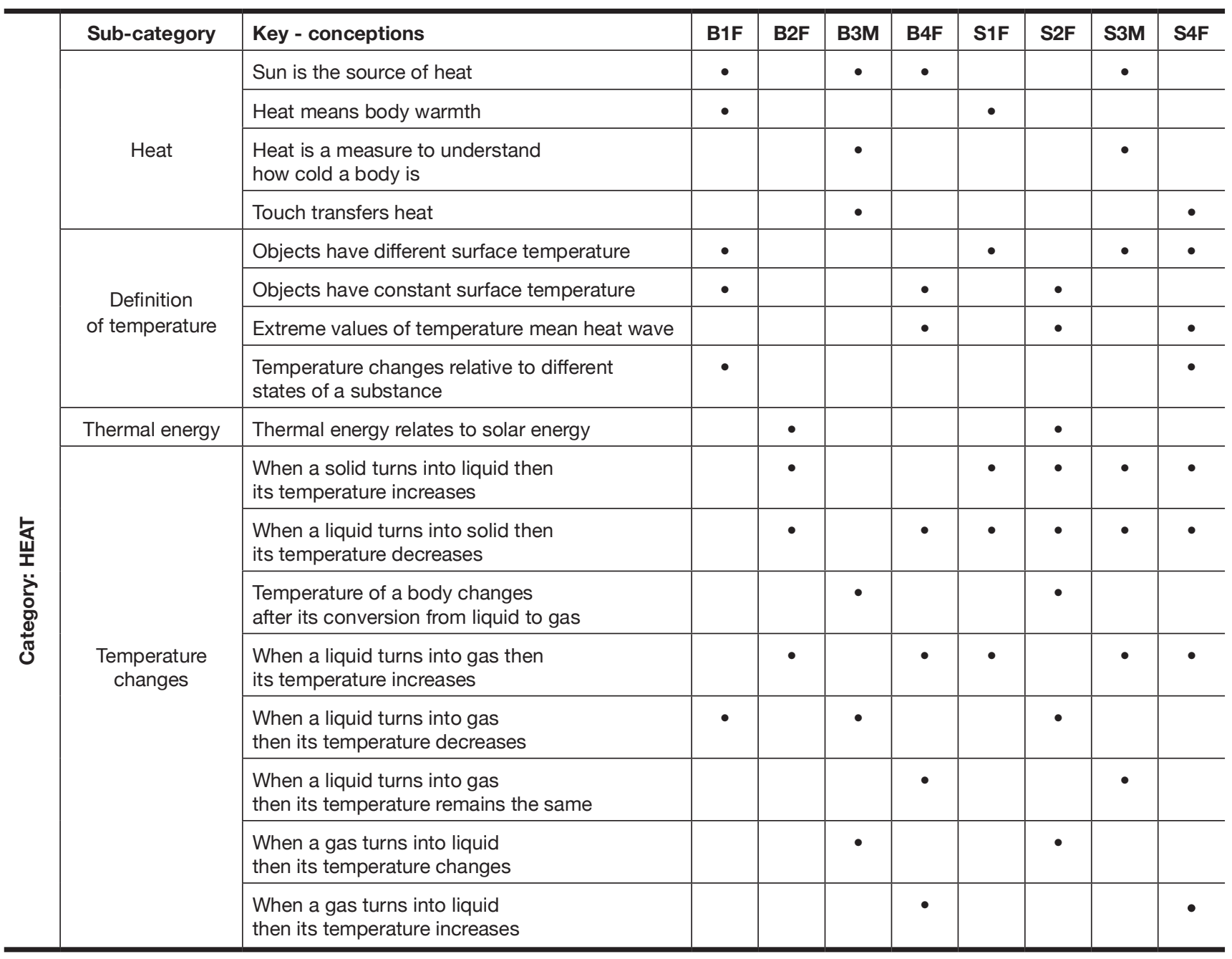


The responses of the sighted participants were closer to scientific explanations but still confusion was traced mainly between the concepts of heat and temperature (see Table 6).

\section{Investigating Common Concepts about "Heat"}

The following table (Table 7) constitutes an aggregated depiction of the common conceptions of participants with and without vision impairments regarding "heat". It seems that confusion between heat and temperature is prevailing in both groups, whereas sighted participants outperformed their blind counterparts in concepts relevant to temperature change.

\section{Investigating Alternative ideas about "Heat"}

A plethora of blind students' alternative ideas concerned the notions of heat, temperature, thermal energy, boiling and the temperature values of a body from one state to the other (the first column of Table 8 ). The analysis sug- gested that the conceptual boundaries between the first three concepts are blurred. Heat and thermal energy are both defined as the temperature of a physical body (or of a space) and vice versa.

The alternative ideas of the sighted participants were organized in four categories. It seems that heat, temperature, and thermal energy are terms that the sighted participants used interchangeably, as if they were the same. A common feature was also the partial understanding of how temperature of a body fluctuates between the physical states (see second column of Table 8). The alternative ideas that were explicitly or implicitly stated by members of both groups are displayed in the third column of Table 8. The common component of those ideas was the use of the terms "heat" and "temperature" as conceptually equivalent. The transfer of heat from a cold body to a warmer one and the identification of "heat" with "thermal energy", were another two commonly shared ideas between the two groups.

Table 8.

Alternative ideas of participants with and without vision impairments (vi) towards the concept of "heat".

\begin{tabular}{|c|c|c|c|}
\hline & participants' statements (with vi) & participants' statements (without vi) & Common statements \\
\hline Heat & $\begin{array}{l}\text { "Heat is when something is hot" } \\
\text { "Heat is the temperature } \\
\text { of a space or of an environment" } \\
\text { "Heat and temperature } \\
\text { are the same" } \\
\text { "Heat is a material body } \\
\text { that changes its temperature" } \\
\text { "Heat is equated with } \\
\text { a warm object" } \\
\text { "Heat can be transmitted from } \\
\text { a cooler to a warmer object" }\end{array}$ & $\begin{array}{c}\text { "Heat is something warm" } \\
\text { "Heat can measure how cold } \\
\text { a body is" } \\
\text { "Heat flows from the cooler } \\
\text { to the warmest body" } \\
\text { "Heat and temperature are the same" } \\
\text { "Cold can be transferred } \\
\text { between different bodies" }\end{array}$ & $\begin{array}{l}\text { "Heat is something warm" } \\
\text { "Heat and temperature } \\
\text { are the same" } \\
\text { "Heat flows from the cooler } \\
\text { to the warmest body" }\end{array}$ \\
\hline Temperature & $\begin{array}{l}\text { "A cold body will have } \\
\text { a temperature below zero" } \\
\text { "A warm body will have } \\
\text { a temperature of over } 20^{\circ} \mathrm{C} \text { " } \\
\text { "Temperature of water falls } \\
\text { after its conversion from ice } \\
\text { to liquid water" }\end{array}$ & $\begin{array}{l}\text { "The temperature measures cold } \\
\text { and hot" } \\
\text { "Changes in temperature affect } \\
\text { liquids rather than solids" } \\
\text { "Temperature is hot or cold" }\end{array}$ & - \\
\hline Thermal energy & $\begin{array}{l}\text { "Thermal energy } \\
\text { is the energy of heat" } \\
\text { "Thermal energy } \\
\text { is the temperature to be } \\
\text { transferred to a body" }\end{array}$ & $\begin{array}{l}\text { "Thermal energy and heat } \\
\text { are the same" } \\
\text { "Thermal energy is the energy } \\
\text { transferred from a warm body } \\
\text { to a different one" }\end{array}$ & $\begin{array}{l}\text { "Thermal energy and heat } \\
\text { are the same" } \\
\text { "Thermal energy is the energy } \\
\text { transferred from a warm body } \\
\text { to a different one" }\end{array}$ \\
\hline $\begin{array}{l}\text { Temperature after } \\
\text { phase changes }\end{array}$ & $\begin{array}{c}\text { "Temperature of a body falls } \\
\text { after its conversion from solid } \\
\text { to liquid" } \\
\text { "Temperature of a body falls } \\
\text { after its conversion from liquid } \\
\text { to gas" } \\
\text { "Temperature of a body remains } \\
\text { stable after its conversion } \\
\text { from liquid to gas" } \\
\text { "Temperature of a body rises } \\
\text { after its conversion from gas } \\
\text { to liquid" }\end{array}$ & $\begin{array}{c}\text { "Temperature of a body falls } \\
\text { after its conversion from liquid to gas" } \\
\text { "Temperature of a body remains } \\
\text { stable after its conversion } \\
\text { from liquid to gas" } \\
\text { "Temperature of a body rises after } \\
\text { its conversion from gas to liquid" }\end{array}$ & $\begin{array}{l}\text { "Temperature of a body } \\
\text { falls after its conversion } \\
\text { from liquid to gas" } \\
\text { "Temperature of a body } \\
\text { remains stable after } \\
\text { its conversion } \\
\text { from liquid to gas" } \\
\text { "Temperature of a body } \\
\text { rises after its conversion } \\
\text { from gas to liquid" }\end{array}$ \\
\hline
\end{tabular}




\section{DISCUSSION}

The main objective of the present study was to investigate the ideas and understandings of individuals with vision impairments about "density" and "heat". Sighted individuals were also part of the investigation so that comparisons could be drawn between the two groups. The overall analysis indicated many points of shared understandings between the two sub-groups.

The results showed that the two subgroups had quite different understanding regarding "density". In particular, the students who were visually impaired provided explanations about "density" based more on their feeling and instinct rather than on theory. This may be due to the fact that "density of a physical body" is an inherently complex concept, as it is unperceivable by the senses and its understanding requires the comprehension of many intrigue concepts (e.g. ratio or proportion) (Xu $\&$ Clarke, 2001). On the other hand, sighted participants' elaborations revealed a primary understanding of the concept. This discrepancy is possibly an indicator of the role of restrictions imposed by the loss of vision in constructing the "density" concept.

While there was no common ground about density in the elaborations of participants with vision impairment, many shared ideas emerged about matter characteristics, which was due to everyday experiences in constructing knowledge about matter properties (Jaworska-Biskup, 2011). These results document the need for teachers to provide their students with many opportunities to explore and examine the properties of matter at different physical states. This is more crucial and necessary for students with vision impairment whose prior knowledge may be limited since incidental learning (Hyams \& Sadique, 2014) is restricted and fragmented. According to Ross and Robinson, "students with visual impairments are unable to take full advantage of unplanned learning" Ross \& Robinson, 2000, p. 331). This is why it is important to ensure that students with vision impairment receive appropriate instruction regarding science education in order to develop exploratory skills and compensate for the absence of incidental learning (Ross \& Robinson, 2000).

Regarding "heat", it seemed that most participants held alternative ideas about the related concepts. There are several factors that may hinder the scientific meaning of the concepts in the context of school science (Sözbi- lir, 2003). These concepts are used in everyday life interchangeably, as if they were the same (for example, heat and temperature), but they have a distinct meaning in the context of school science. Daily life experiences as well as the instruction provided in these content areas may also promote or reinforce alternative ideas.

In conclusion, participants with vision impairments held numerous alternative ideas about the two concepts. The same pattern was noticed in the group of their sighted peers. On the other hand, the results revealed many points of common understanding between the two subgroups, but also some points of divergence. Whatever the differentiations or adaptations may be in science labs, teachers need to investigate blind students' alternative ideas in advance and work them out with them. In addition, students with vision impairment observe first the parts of a phenomenon or of an experiment and then they are invited to mentally construct the whole, which is a more challenging way to learn and hence to elaborate (Millar, 2006). Therefore, science teachers' education should be consistent and aligned with current educational trends so that teachers can use effective instruction, appropriate technological advances, and differentiated content. (Argyropoulos \& Gentle, 2019). According to Maguvhe (2015), the science curriculum is usually inaccessible to students with vision impairments and science teachers are not trained to teach students with vision impairments. What is more, there are no specialized labs to support students with vision impairment. Since, the vast majority of students with vision impairment are enrolled in general educational settings, the necessity of having trained science teachers, adapted science labs, availability of assistive technology and differentiated curricula is crucial and vital. The example of the expanded core curriculum may serve all the above needs very well and set basic principles into an integrated school where students with vision impairment are enrolled (Brown \& Glaser, 2014).

Finally, it has to mentioned that researchers have criticized comparative methods as inadequate and unstable (i. e. students with visual impairments and sighted peers, Warren, 1994) since these methods seek comparisons between different populations instead of seeking explanations within a population. However, the information which has been obtained by comparative studies concerning scientific concepts should not be rejected altogether as it constitutes the main source of data. In relation to this, Lewis and Collis (1997) support the view 
that the opinions concerning cognitive development are bound to be influenced by comparative studies with the "norm". Warren (1994) advocates this as well, assuming that one should not completely dismiss the information that is obtained from comparative studies by taking the sighted population as the „norm” because:

The development of all children is governed to some degree by maturation, and since development occurs within environments that, though they differ in specifics, have major domains in common, we should expect some basic commonalities of development among all children...the principles and basic dynamics of development are fundamentally the same for children with and without visual impairments (p4-5).

Since, the findings demonstrated that there were common patterns of alternative ideas in both subgroups, it may lead to the assumption that vision loss or blindness and proficiency in science do not constitute a causal relation.

\section{LIMITATIONS AND CONCLUSION}

One basic limitation is the fact that with such a small number of participants, these results cannot be generalized. Also, another limitation that may have impacted the results is the fact that age, development, years of exposure to the topic (i.e. density and heat) were not taken into account in this pilot study. Nevertheless, although the outcomes of the present study cannot be generalized due to the small sample, they support the idea of expanding the general science curriculum by adding additional purposeful hands-on experiences in conjunction with advanced technological advances in order to promote blind students' scientific thinking and learning (Darrah, 2013; Nam, Li, Yamaguchi, \& Smith-Jackson, 2012; Supalo, Isaacson, \& Lombardi, 2014; Siu \& Morash, 2014).

\section{ACKNOWLEDGEMENT}

None.

\section{DISCLOSURE STATEMENT}

No potential conflict of interest

was reported by the authors.

FUNDING: None.

\section{REFERENCES}

Ambrose-Zaken, G., \& Bozeman, L. (2010). Profile of personnel preparation programs in visual impairment and their faculty. Journal of Visual Impairment \& Blindness, 104, 148-169.

Argyropoulos V., \& Ravenscroft J. (2019). Assisting People with Vision Impairments through Technology. In: A. Tatnall (Ed.), Encyclopedia of Education and Information Technologies (pp. 1-10). Cham: Springer Nature.

Argyropoulos, V., \& Gentle, F. (2019). Formal and non-formal education for individuals with vision impairment or multiple disabilities and vision impairment. In J. Ravenscroft (d.) The Routledge Handbook of Visual Impairment (pp. 118-142). Abingdon: Routledge.

Betts, L. R., \& Cross, A. (2010). Reflections on supporting a visually impaired student complete biological psychology module. Psychology Teaching Review, 16(1), 58-60.

Brown, L. C. \& Glaser, S. (2014). Teaching the expanded core curriculum in general education settings. In C. B. Allman \& S. Lewis (Eds.). ECC Essentials. Teaching the Expanded Core Curriculum to Students with Visual Impairments (pp. 513-554). AFB Press.

Cohen, L., Manion, L., \& Morrison, K. (2007). Research Methods in Education. London: Routledge.

Darrah, M. (2013). eTouch sciences apps: A new way to interact with math and science content. from https://nfb.org/images/nfb/publications/fr/fr32/3/fr320305.htm

Dey, I. (1993). Qualitative data analysis: a user-friendly guide for social scientists. Routledge: London.

Fraser, W. J., and Maguvhe, O. (2008). Teaching life sciences to blind and visually impaired learners. Journal of Biological Education, 42, 84 - 89.

Hyams, R. \& Sadique, D. (2014). The value of incidental learning in a multidisciplinary setting. International Journal of Clinical Legal Education, 20, 439-459.

Jaworska-Biskup, K. (2011). The world without sight. A comparative study of concept understanding in polish congenitally totally blind and sighted children. Psychology of Language and Communication, 15, 27-47.

Jones, M. G., Forrester, J. H., Robertson, L. E., Gardner, G. E., and Taylor, A. R. (2012). Accuracy of estimations of measurements by students with visual impairments. Journal of Visual Impairment \& Blindness, 106, $351-355$.

Jones, M. G., Minogue, J., Oppewal, T., Cook, M. P., \& Broadwell, B. (2006). Visualizing without vision at the microscale: students with visual impairments explore cells with touch. Journal of Science Education and Technology, 15, 345-351. 
Jones, M. G., Taylor, A. R., \& Broadwell, B. (2009). Concepts of scale held by students with visual impairment. Journal of Research in Science Teaching, 46(5), 506-519.

Kumar, D., Ramasamy, R. \& Stefanich, G. (2001). Science for students with visual impairments: Teaching suggestions and policy implications for secondary educators. Electronic Journal of Science Education, 5, 3-4.

Lewis, V., \& Collis G.M. (1997). Blindness and Psychological Development in Young Children. Leicester: UK: The British Psychological Society.

Maguvhe, M. (2015). Teaching science and mathematics to students with visual impairments: Reflections of a visually impaired technician. African journal of disability, 4(1). Art. \#194, 6 pages. http://dx.doi. org/10.4102/ajod.v4i1.194.

Matchinski, T. L., \& Winters, J. E. (2016). A Comparison of Subjects' Reading and Writing Performance and Preference While Using Various Portable Electronic Magnifiers. Journal of Visual Impairment \& Blindness, 110, 454-460.

Merriam, S. B. (2009). Qualitative Research: A guide to design and implementation. San Francisco, Calif.: Jossey-Bass.

Micklos, A. L., \& Bodner, G. $\square$ (2013). Chemical reactions: what understanding do students with blindness develop? Chemistry Education Research and Practice, 14, 625-636.

Millar, S. (2006). Processing Spatial Information from Touch and Movement: Implications from and for Neuroscience. In M. A. Heller \& S. Ballesteros (Eds.), Touch and Blindness (pp. 25-48). New Jersey: Lawrence Erlbaum Associates.

Nam, S. C., Li, Y., Yamaguchi, T., \& Smith-Jackson, T. L. (2012). Haptic user interfaces for the visually impaired: Implications for haptically enhanced science learning systems. International Journal of Human-Computer Interaction, 28, 784-798.

Nkiko, C., Atinmo, M. I., Michael-Onuoha, H. C., Ilogho, J. E., Fagbohun, M. O., Ifeakachuku, O., Adetomiwa B., Usman, K. O. (2018). Information Technology and Transcription of Reading Materials for the Visually Impaired Persons in Nigeria. Journal of Education and Learning, 7, 42-52.

Robson, C. (1997). Real World Research. Oxford: Blackwell.

Rosengren, K. S. \& Brawell, G. S. (2002). Variability in children's reasoning. Advances in Child Development and Behavior, 28, 1-40.

Ross, D. B. \& Robinson, M. C. (2000). Social studies and science. In A. J. Koenig \& M. C. Holbrook (Eds.), Foundations of Education. Vol. II, (pp. 330-357). NY: AFB Press.

Sahin, M., \& Yorek, N. (2009). Teaching science to visually impaired students: a small-scale qualitative study. US-China Education Review, 6, 19-26.

Siu, Y. T., \& Morash, V. S. (2014). Teachers of students with visual impairments and their use of assistive technology: measuring the proficiency of teachers and their identification with a community of practice. Journal of Visual Impairment \& Blindness, 108(5), 384-398.

Smothers, S. M., \& Goldston, M. J. (2009). Atoms, elements, molecules, and matter an investigation into the congenitally blind adolescents' conceptual frameworks on the nature of matter. Science Education, 94, 448-477.

Soltanifar, E. \&Ansari, M. (2016). Matrix-Collage: An Innovative Methodology for Qualitative Inquiry in Social Systems. The Electronic Journal of Business Research Methods, 14, 8-27.

Sözbilir, M. (2003). A review of selected literature on students' misconceptions of heat and temperature. Boğaziçi University Journal of Education, 20, 25-41.

Supalo, C. A., Isaacson, M. D., \& Lombardi, M. V. (2014). Making hands-on science learning accessible for students who are blind or have low vision. Journal of Chemical Education, 91, 195-199.

Wandersee, J. H., Mintzes, J. J., \& Novak, J. D. (1994). Research on alternative conceptions in science. In D. L. Gabel (Eds.), Handbook of research on science teaching and learning (pp. 177-210). New York: Simon \& Schuster and Prentice Hall International.

Warren, D.H. (1994). Blindness and Children. An individual Differences Approach. Cambridge University Press.

Wild, T. A. (2010). Talking turkey: teaching about America's greatest conservation story with children with visual impairments. Journal of Visual Impairment \& Blindness, 104, 198-201.

Wild, T. A., \& Trundle, K. C. (2010). Conceptual understandings of seasonal change by middle school students with visual impairments. Journal of Visual Impairment \& Blindness, 104, 107-118.

Wild, T. A., Hilson, M. P., \& Farrand, K. M. (2013). Conceptual understanding of geological concepts by students with visual impairments. Journal of Geoscience education, 61, 222-230.

Wild, T. A., Hilson, M. P., \& Hobson, S. M. (2013). The conceptual understanding of sound by students with visual impairments. Journal of Visual Impairment \& Blindness, 107, 107-116.

Wild, T., \& Allen, A. (2009). Policy analysis of science-based best practices for students with visual impairments. Journal of Visual Impairment \& Blindness, 103, 113-117.

Xu, L., \& Clarke, D. (2011). Student difficulties in learning density: a distributed cognition perspective. Research in Science Education, 42, 769-789. 